\title{
O USO DE GEOTECNOLOGIAS ASSOCIADO A METODOLOGIAS PARTICIPATIVAS NO ENSINO: APLICAÇÃO EM ESCOLAS MUNICIPAIS DO PRIMEIRO DISTRITO DE PETRÓPOLIS
}

The use of geotechnologies associated with participatory methodologies in teaching: application in municipal schools of the first Petrópolis distric

El uso de geotecnologías asociado a metodologías participativas en la enseñanza: aplicación en escuelas municipales del primer distrito de Petrópolis

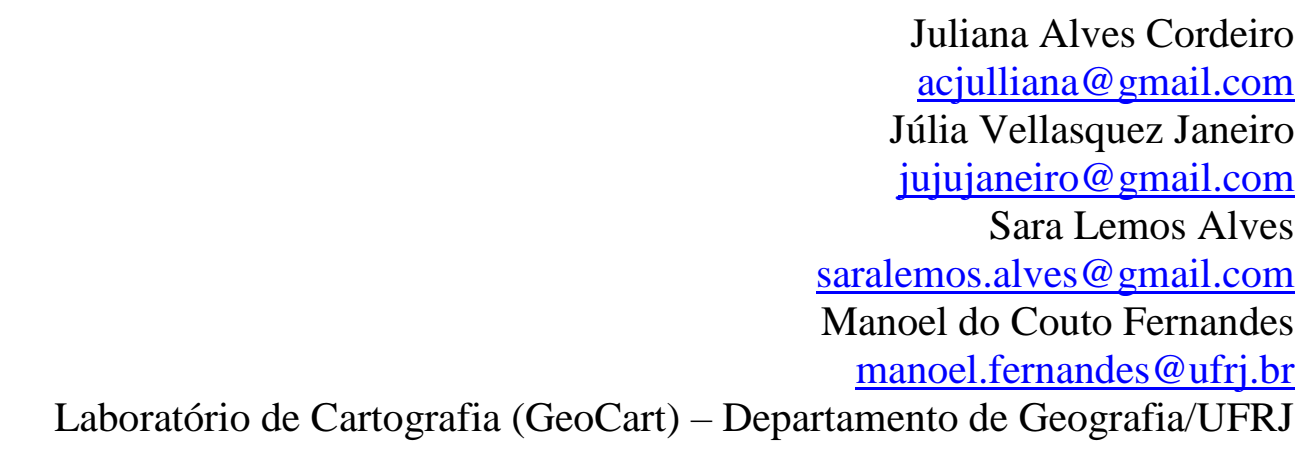

Enviado em 31/10/2018 e aceito para publicação em 01/12/2018

DOI: $10.12957 /$ tamoios.2018.38081

\section{RESUMO}

Embora a difusão das geotecnologias já seja uma realidade cotidiana, sua inserção como ferramenta de apoio no ensino ainda é incipiente. Essas geotecnologias associadas às metodologias participativas na aplicação escolar, permitem o envolvimento direto dos alunos no processo de produção das informações geográficas e na confecção dos mapas. Dessa forma, o presente trabalho propôs a criação de uma proposta metodológica de atividade escolar baseada na utilização de geotecnologias associada a metodologias participativas para atender as demandas dos eixos temáticos da disciplina de História, Geografia, Turismo e Educação para o Trânsito de Petrópolis (HGPT-ET). A metodologia do trabalho dividiu-se em três etapas: a análise e leitura do referencial curricular do ensino fundamental e dos cadernos pedagógicos; a definição da atividade e da ferramenta a ser utilizada e, por fim, a realização de oficinas práticas em duas escolas municipais. Como resultados, obteve-se um mapa em versões interativa e analógica do município de Petrópolis com os pontos e as informações coletadas pelos alunos. A proposta metodológica possui o intuito de servir não apenas como exercício, mas como material pedagógico da disciplina específica sobre a cidade, preenchendo uma lacuna de materiais didáticos sobre Petrópolis.

Palavras-chave: geotecnologias, metodologias participativas, proposta metodológica, HGPT-ET, ensino. 


\begin{abstract}
Although the diffusion of geotechnologies is already a daily reality, its insertion as a support tool in education is still incipient. These geotechnologies, associated with participatory methodologies in school applications, allow the direct involvement of students in the process of producing geographic information and in the making of maps. Thus, the present work proposed the creation of a methodological proposal of school activity based on the use of geotechnologies associated with participatory methodologies to meet the demands of the thematic axes of the History, Geography, Tourism and Education for Transit of Petropolis (HGPT- ET). The methodology of the work was divided in three stages: the analysis and reading of the curricular reference of the elementary school and the pedagogical notebooks; the definition of the activity and the tool to be used and, finally, the realization of practical workshops in two municipal schools. As results, a map was obtained in interactive and analog versions of the municipality of Petrópolis with the points and information collected by the students. The methodological proposal aims to serve not only as an exercise, but as pedagogical material of the specific discipline about the city, filling a gap of didactic material on Petropolis.
\end{abstract}

Keywords: geotechnologies, participatory methodologies, methodological proposal, HGPT-ET, teaching.

\title{
RESUMEN
}

Aunque la difusión de las geotecnologías ya sea una realidad cotidiana, su inserción como herramienta de apoyo en la enseñanza todavía es incipiente. Estas geotecnologías asociadas a las metodologías participativas en la aplicación escolar, permiten la participación directa de los alumnos en el proceso de producción de las informaciones geográficas y en la confección de los mapas. De esta forma, el presente trabajo propuso la creación de una propuesta metodológica de actividad escolar basada en la utilización de geotecnologías asociada a metodologías participativas para atender las demandas de los ejes temáticos de la disciplina de Historia, Geografía, Turismo y Educación para el Tráfico de Petrópolis (HGPT-ET). La metodología del trabajo se dividió en tres etapas: el análisis y lectura del referencial curricular de la enseñanza fundamental y de los cuadernos pedagógicos; la definición de la actividad y de la herramienta a ser utilizada y, finalmente, la realización de talleres prácticos en dos escuelas municipales. Como resultados, se obtuvo un mapa en versiones interactiva y analógica del municipio de Petrópolis con los puntos y las informaciones recogidas por los alumnos. La propuesta metodológica tiene el propósito de servir no sólo como ejercicio, sino como material pedagógico de la disciplina específica sobre la ciudad, llenando una laguna de materiales didácticos sobre Petrópolis.

Palabras clave: geotecnologías, metodologías participativas, propuesta metodológica, HGPT-ET, enseñanza. 


\section{INTRODUÇÃO}

A emergência das inovações tecnológicas, já enraizadas na sociedade contemporânea, permitiu novas possibilidades de comunicação e de transmissão de informações. Embora as geotecnologias também façam parte da realidade cotidiana, principalmente pelo uso de ferramentas como Google Maps, Google Earth, Waze, entre outros, seu uso como uma ferramenta pedagógica ainda é incipiente, apesar do seu enorme potencial para este fim. Por meio da utilização dessas geotecnologias, sobretudo no ensino de Geografia, o professor tem a possibilidade de dinamizar as aulas, tornando-as mais interessantes e práticas, estimulando a curiosidade e o raciocínio espacial dos alunos.

Segundo Vieira (2015) é imprescindível que os alunos nas séries iniciais da educação básica tenham a aprendizagem de noções espaciais, tornando-se essencial a capacidade de leitura do espaço. Possuir a habilidade de ler o espaço também infere na compreensão de uma linguagem cartográfica.

Diversos autores dentre eles (SIMIELLI, 1993; ALMEIDA, PASSINI, 1994; CASTELLAR, 1996; MARTINELLI, 2010) dedicaram-se a pesquisas sobre as possibilidades da Cartografia na educação básica. E, muitos desses estudos apontam que a Cartografia deve ser utilizada não apenas como um conteúdo, mas sim como uma linguagem, a partir da leitura das realidades vivenciadas pelos alunos. Dessa forma, o papel dos professores não está apenas em ensinar a Cartografia, mas ensinar através dela.

Diante deste pensamento há ainda o reconhecimento de importantes mudanças no modo de produzir as informações geográficas, e na confecção de mapas, além da inserção de novos atores neste processo, “(...) traz uma nova dimensão à cartografia: a de que o usuário pode não ser apenas um "leitor", mas um "criador" de mapas" (ALVES, 2016, p.10).

O uso de metodologias participativas (Chaves, 2011) associadas às geotecnologias para aplicação escolar permite o envolvimento direto dos alunos no processo de produção de informações geográficas e na confecção de seus próprios mapas, podendo, assim, ser um elemento facilitador para o entendimento dos conteúdos geográficos e cartográficos abordados, que por muitas vezes são de difícil compreensão (ROSA, 2005).

De maneira a estimular a discussão sobre as novas ferramentas para o ensino de Geografia, somados às possibilidades da utilização de metodologias participativas, o presente trabalho tem como objetivo geral a criação de uma proposta metodológica de atividade escolar baseada na utilização de geotecnologias para atender as demandas dos eixos temáticos da disciplina de História, Geografia, Turismo e Educação para o Trânsito de Petrópolis, que diz respeito à história da fundação da cidade bem como sua forte influência da colonização europeia. Esta disciplina é definida pelo Referencial Curricular da Rede Municipal e obrigatória no currículo escolar (Lei no 1984 - Diário Oficial de 29/12/1984).

O trabalho abrange o primeiro distrito do município de Petrópolis, que é uma unidade territorial que contempla a área de gênese do município e que possui uma posição histórica no país. A pesquisa se desenvolveu com os alunos da E.M. Dr. Rubens de Castro Bomtempo e E.M. Paroquial Bom Jesus a partir da realização de oficinas práticas, onde foi possível, a produção de um mapa interativo e analógico com pontos de interesse e/ou turísticos do município de Petrópolis baseados na escolha dos alunos.

A divulgação das geotecnologias como recurso didático-pedagógico que muito tem a oferecer apoiando os conteúdos geográficos e cartográficos, enfatiza a noção da emergência de mudanças no paradigma nas aulas de Geografia. Que, na identificação de lacunas, principalmente no que tange à linguagem cartográfica, apresentam-se como 
alternativas de métodos de ensino (OLIVEIRA, 2006). Sendo assim, postulam-se os objetivos da pesquisa que fundamentam o presente trabalho.

\section{ÁREA DE ESTUDO}

O município de Petrópolis está localizado na região serrana ao norte do estado do Rio de Janeiro, sendo reconhecido pelo seu grande potencial turístico, muito atrelado a história de fundação da cidade. Sua configuração espacial está diretamente associada ao processo de ocupação no século XVII até sua consolidação como o local de veraneio da Família Imperial somados aos intensos fluxos migratórios de colonos europeus no século XIX, representando papel relevante no contexto nacional.

A divisão distrital atual da cidade é caracterizada em cinco distritos: Petrópolis, Cascatinha, Itaipava, Pedro do Rio e Posse. O trabalho se desenvolveu no $1^{\circ}$ distrito que é denominado Petrópolis, por ser a área planejada que abrigou os quarteirões e as vilas do Plano-Palácio de Petrópolis, sendo considerada a área gênese de ocupação da cidade (Figura 1). Dessa forma, a organização espacial local assim como sua arquitetura singular com palacetes faz parte do patrimônio arquitetônico do Centro Histórico da cidade, cuja preservação é imprescindível para o desenvolvimento turístico e cultural de Petrópolis.

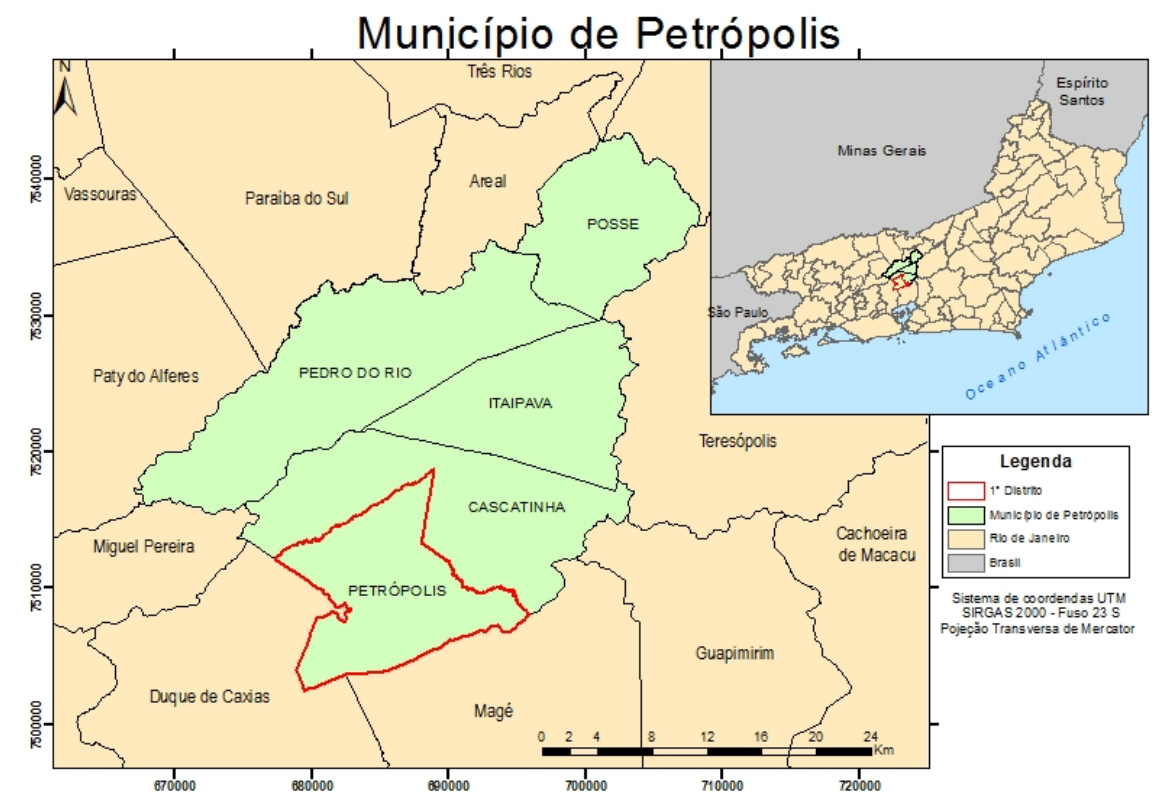

Figura 1: Localização do município de Petrópolis

\section{METODOLOGIA}

A metodologia do trabalho foi dividida em três etapas: a primeira consistiu na leitura e análise do Referencial Curricular da Rede Municipal de Petrópolis e dos cadernos pedagógicos da disciplina de HGPT-ET do segundo segmento do ensino fundamental; a segunda, no processo de escolha da atividade e da ferramenta a ser utilizada; e a terceira e última, realizou-se com a aplicação da atividade através de oficinas práticas e a elaboração dos mapas interativo e analógico com os alunos. 


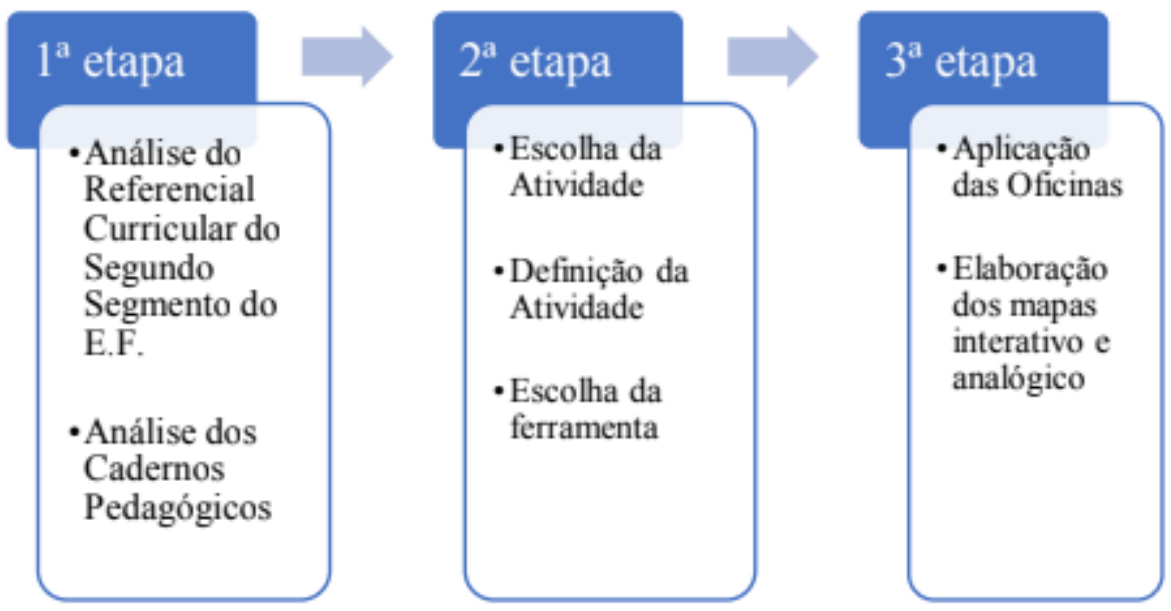

Figura 2. Metodologia da proposta metodológica dividida em etapas

\section{O REFERENCIAL CURRICULAR DA REDE MUNICIPAL DE PETRÓPOLIS E A DISCIPLINA HGPT-ET}

O Referencial Curricular da Rede Municipal de Petrópolis passou por uma reformulação no ano de 2015 de forma a atender as necessidades vigentes das escolas municipais de todo o município. Um dos pontos interessantes destacados neste documento são os desafios contemporâneos enfrentados pela educação, dentre eles a desigualdade de acesso ao uso das tecnologias que hoje mediam o acesso ao conhecimento. Desigualdades e exclusões que também são presentes nas escolas, principalmente na rede pública de ensino com ausência de infraestrutura como salas de informática e a capacitação e conhecimento dos docentes em relação às potencialidades das novas tecnologias existentes que poderiam ser utilizadas como ferramentas de apoio no ensino.

A presença da tecnologia no cotidiano denota um ritmo sem precedentes no acúmulo de conhecimentos, gerando uma transformação profunda na sua estrutura e nas suas formas de organização e distribuição (SECRETARIA DE EDUCAÇÃO DE PETRÓPOLIS, 2014). Em contrapartida, é válido destacar como o autor Rosa (2014) bem pontua, que as escolas não devem se deslumbrar ingenuamente com a introdução da tecnologia em si, pois ela sozinha não representará a solução dos problemas da educação brasileira.

A disciplina História, Geografia, Turismo e Educação para o Trânsito de Petrópolis como afirmado anteriormente é matéria obrigatória no currículo escolar da Rede Municipal de Petrópolis. O seu principal objetivo consiste em estimular nos alunos a curiosidade sobre a história da fundação da cidade e a sua localização espacial além de incentivar a formação de uma visão crítica do aluno em relação aos conteúdos apresentados, elevando o sentimento de pertencimento e valorização do espaço, história e a cultura local (SECRETARIA DE EDUCAÇÃO DE PETRÓPOLIS, 2014).

\section{A ELABORAÇÃO DA PROPOSTA METODOLÓGICA}

Conforme o desejo por parte dos proponentes do trabalho em criar a proposta metodológica utilizando geotecnologias, acreditava-se que a última série do segundo 
segmento do ensino fundamental aceitaria essa atividade escolar de forma satisfatória tornando o enfoque da análise do caderno pedagógico desta série. Durante a leitura e a análise dos cadernos pedagógicos do $9^{\circ}$ ano, foi identificado a predominância de conteúdos referentes à história de fundação da cidade. A partir disso, pensou-se na elaboração da atividade em torno dessa temática, que culminou na criação do exercício que envolvia a produção de um mapa interativo online com pontos de interesse e/ou turísticos da cidade de Petrópolis, bem como as suas informações, baseados na visão dos alunos.

Para a execução da atividade, os alunos deveriam escolher locais que consideravam interessantes para serem mostrados a um turista, por exemplo, não necessariamente sendo um ponto turístico conhecido. Diante da definição da atividade, o próximo passo consistiu na escolha da ferramenta a ser utilizada. Neste processo foram levados em consideração alguns critérios que implicaram diretamente na viabilidade da atividade, dentre eles a facilidade de manuseio dos alunos e a necessidade da ferramenta ser online e gratuita.

Posto estes critérios, a ferramenta escolhida foi o Google MyMaps. Esta plataforma do Google permite que os usuários façam a customização assim como o compartilhamento de mapas personalizados a partir da base do Google Maps. Também é possível adicionar pontos, linhas e rotas nesta plataforma além de inserir camadas personalizando os itens de cada camada com estilos próprios.

A atividade foi realizada em duas escolas da rede municipal de Petrópolis: a Escola Municipal Doutor Rubens de Castro Bomtempo e a Escola Municipal Paroquial Bom Jesus. A primeira está situada na Vila Felipe, na localidade Alto da Serra, e a segunda está localizada no Quitandinha. Porém, mesmo que a proposta metodológica tenha sido aplicada nas duas escolas, tal aplicação não foi realizada da mesma maneira.

Na E.M. Dr. Rubens de Castro Bomtempo foram promovidos três encontros para a realização da atividade no próprio ambiente escolar, enquanto que os alunos da E.M. Paroquial Bom Jesus realizaram a atividade no Laboratório de Cartografia (GeoCart), do Departamento de Geografia da Universidade Federal do Rio de Janeiro, pois em seu cronograma escolar já estava programado uma visita ao Museu da Geodiversidade, também situado na UFRJ.

Neste processo de definição da atividade, surgiram dois desdobramentos e desafios na pesquisa. O primeiro foi identificado na E.M. Dr. Rubens de Castro Bomtempo, no qual foram feitas visitas prévias às instalações da escola, a fim de apresentar a proposta para a coordenação do colégio bem como à professora responsável pela disciplina.

Com base nessas visitas, foi possível identificar a ausência de Internet, apesar da presença de um laboratório de informática. Uma solução encontrada para viabilizar a atividade foi a explicação da funcionalidade da ferramenta aos alunos utilizando Internet móvel e a aplicação de questionários com informações que posteriormente seriam inseridas manualmente nos mapas pelas proponentes da atividade. $\mathrm{O}$ mesmo questionário foi aplicado aos alunos da E.M. Paroquial Bom Jesus, entretanto, estes representaram os pontos e inseriram as informações coletadas diretamente na base cartográfica do Google MyMaps.

O segundo desafio percebido foi pelo reconhecimento de que para ter acesso ao Google MyMaps os alunos precisariam ter uma conta de e-mail vinculado ao Google muitos poderiam não ter pela dificuldade de acesso à internet, a não utilização de e-mail, entre outros - o que levou posteriormente ao seguinte questionamento: de que maneira os alunos poderiam editar o mesmo mapa ao mesmo tempo? Diante destes desdobramentos, a solução encontrada foi a criação de uma conta de e-mail específica para a atividade, de 
forma que os alunos pudessem utilizar o MyMaps conectados em diferentes computadores ao mesmo tempo e que pudessem editar o mesmo mapa.

\section{APLICAÇÃO DAS OFICINAS PRÁTICAS}

As oficinas práticas foram elaboradas a partir das necessidades observadas nos eixos temáticos da disciplina HGPT-ET mas, em contrapartida a aplicação das oficinas em ambas as escolas ocorreu de formas diferentes. A experiência com os alunos da Dr. Rubens de Castro Bomtempo culminou no total de três encontros com duração de 50 minutos cada diante dos desafios encontrados associados a ausência de infraestrutura necessária para a realização da proposta metodológica.

Cabe ressaltar que foi decidido em conjunto com a professora da disciplina bem como à coordenação, que a atividade nesta escola iria compor a avaliação da disciplina. Foi proposto dessa maneira, que fosse realizado um seminário de modo que os alunos apresentassem em forma de cartazes e/ou apresentações em slides, informações a respeito dos pontos escolhidos. Estes encontros consistiam na explicação da proposta; da funcionalidade do MyMaps assim como os conceitos pertinentes ao trabalho (geotecnologias, metodologias participativas e mapas temáticos); na coleta dos questionários com as informações e a apresentação dos seminários.

Em contrapartida, através da experiência com os alunos da E.M. Paroquial Bom Jesus, em apenas um encontro, foi explicado aos jovens à proposta metodológica e os conceitos. Estes tiveram a oportunidade de entrar em contato direto com a ferramenta, onde puderam representar os pontos escolhidos bem como a inserção das informações na base cartográfica do MyMaps.

\section{RESULTADOS E DISCUSSÃO}

De acordo com os desafios enfrentados ao decorrer da elaboração da proposta metodológica, a ausência de infraestrutura necessária para a utilização das geotecnologias implicou na necessidade da utilização de três aulas na Rubens de Castro Bomtempo. Porém, a atividade em si não foi inviabilizada por completa já que foi mostrada aos alunos através de Internet Móvel as funcionalidades do Google MyMaps assim como os produtos gerados a partir dessa atividade, os mapas interativo e analógico produzidos pela escolha e pesquisa de informações dos pontos por esses estudantes. Em contrapartida, através da experiência com os alunos da Paroquial Bom Jesus foi possível identificar a possibilidade de aplicação da atividade em uma única aula.

O comportamento e aceitação da proposta metodológica dos alunos foi um importante ponto a ser observado, já que as atividades ocorreram de formas diferenciadas nas duas escolas. Apesar de a atividade escolar ter feito parte da avaliação dos alunos da E. M. Dr. Rubens de Castro Bomtempo, esperava-se que estes se interessassem mais pela atividade, o que não ocorreu. Por outro lado, os alunos da E. M. Paroquial Bom Jesus demonstraram maior interesse pela atividade, ainda que não fizesse parte da avaliação da disciplina. Uma justificativa para essa maior aceitação pode ser o fato de que estes estavam fora do ambiente escolar, em um laboratório de pesquisa de uma universidade, permitindo um contato e interação em outro ambiente. Além disso, o contato direto com a ferramenta e possibilidade de navegação e exploração dela pode ter contribuído para um maior empenho com a atividade.

Como resultado das oficinas práticas, obteve-se o mapa interativo com todos os pontos representados e suas informações, fornecidos pelos alunos de ambas as escolas (Figura 2), além do mapa analógico que foi produzido através do software gratuito Google 
Earth pelos proponentes da pesquisa para visualização dos alunos da E.M. Dr. Rubens de Castro Bomtempo (Figura 3), visto que eles não tinham acesso à internet para fazer a navegação. Para facilitar a leitura e a interpretação dos mapas, foi atribuído o mesmo símbolo para os atrativos, porém com diferentes cores de acordo com o tipo (museu, monumento, praça, restaurante, entre outros). Foram criadas duas camadas - uma para cada escola - junto às informações de cada ponto (endereço, tipo de atrativo, período de fundação, origem do fundador, curiosidades, entre outros).

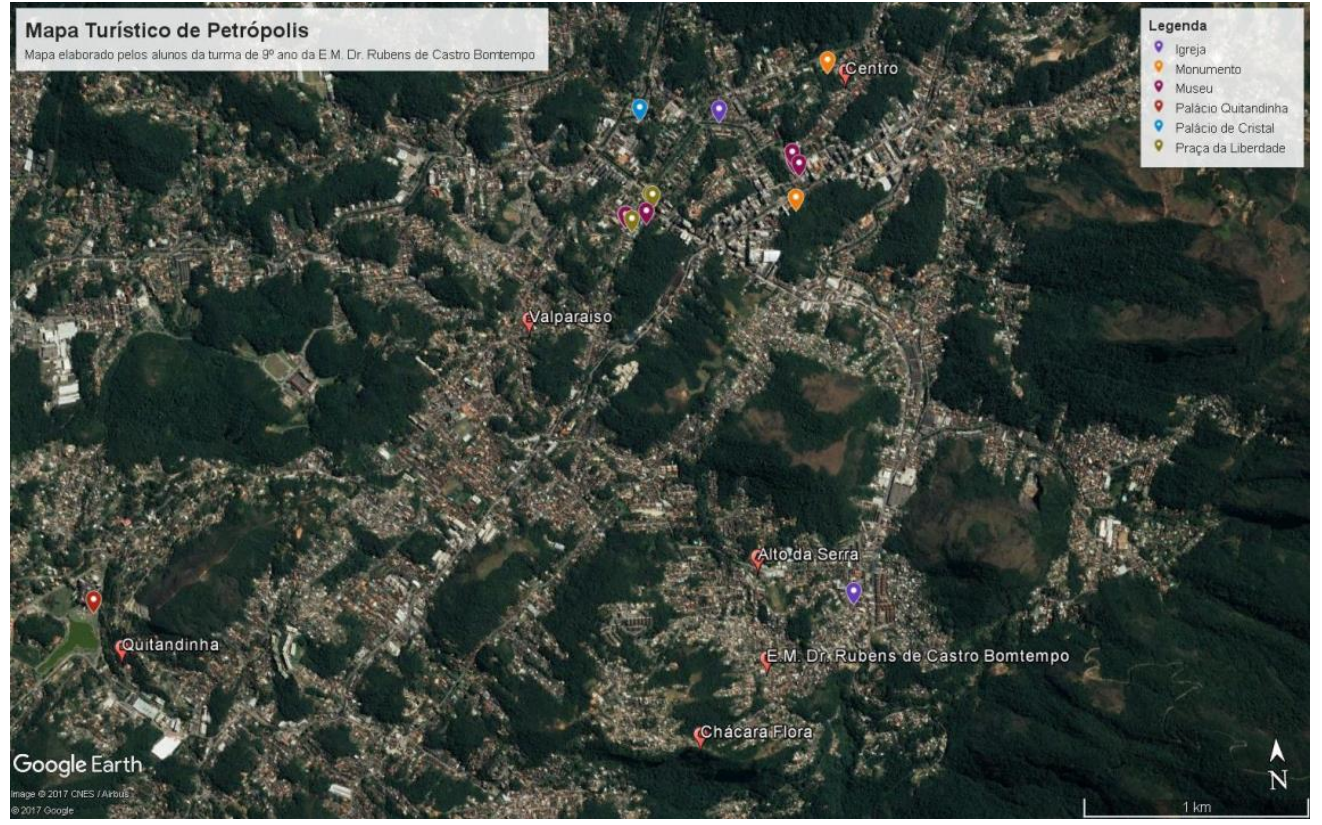

Figura 3. Mapa final com os pontos escolhidos dos alunos no MyMaps. Disponível em: <https://www.google.com/maps/d/edit?mid=11XJkPtsqPZBnP_IISO893FhYrt8\&ll=$11.81132777279309 \% 2 \mathrm{C}-51.92527949999999 \& \mathrm{z}=4>$

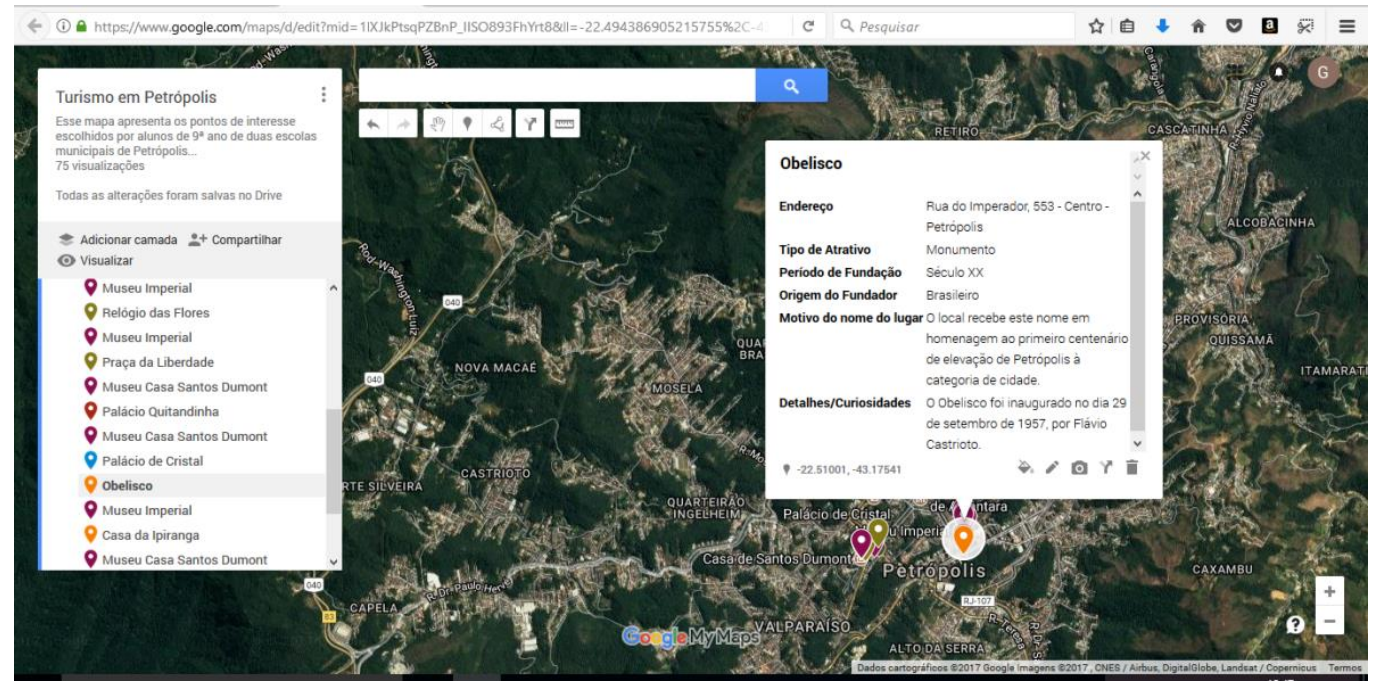

Figura 4. Mapa analógico com os pontos escolhidos pelos alunos da Dr. Rubens de Castro Bomtempo

Com base na escolha dos pontos de interesse dos alunos, foi possível identificar o predomínio dos pontos turísticos da cidade de Petrópolis. Ainda que tenha sido explicado que a escolha dos locais era livre, os alunos indicaram os pontos turísticos, em sua maioria, para serem representados, caracterizando uma forte influência histórica da 
cidade no processo de escolha destes alunos. Dentre os pontos turísticos que ganharam destaque, o tipo de atrativo "museu" predominou em ambas as escolas.

Apesar dos pontos turísticos terem sido a escolha da maioria, alguns alunos optaram por outros locais que para eles também apresentavam relevância. Um aluno escolheu a própria casa como um local para ser mostrado para um turista, pois segundo o seu relato, este não possuía condições financeiras para conhecer e frequentar diferentes locais de Petrópolis, somado ao fato de que para ele, seria interessante mostrar para outra pessoa o ambiente em que ele mora, e que outros membros da sua família também viviam. Outro aluno escolheu a Igreja Santo Antônio, que fica localizada na Vila Felipe, próxima à sua casa e de sua escola, como um ponto de encontro da vizinhança e da sua família. É neste ponto que a atividade corrobora com o objetivo da disciplina de fortalecer o sentimento de pertencimento ao espaço da cidade.

Ressalta-se que este processo de escolha de um "ponto de interesse" é subjetivo e que a todo o momento da atividade escolar, foi respeitado e mantido, já que o intuito desta atividade era estimular a visão do aluno sobre o espaço geográfico e o lugar no qual está inserido, de modo que este escolhesse um local que para ele tivesse algum tipo de significado e valor.

Tipos de Atrativos - Geral

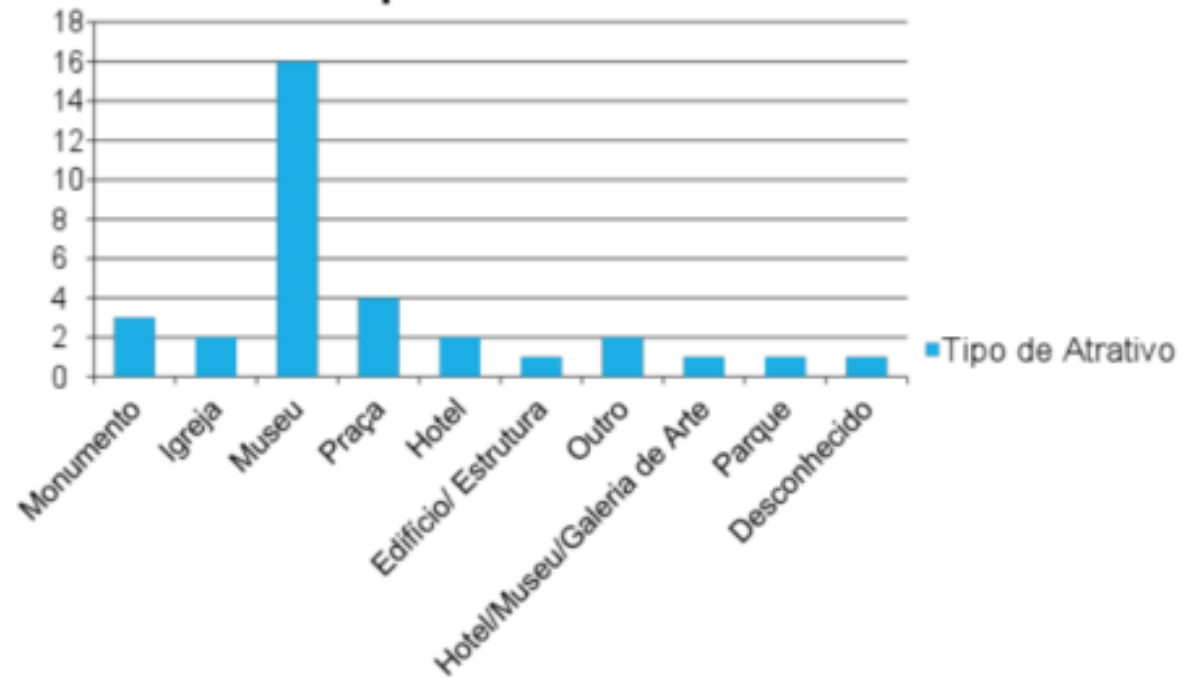

Figura 5. Tipos de atrativos escolhidos pelos alunos das duas escolas

\section{CONCLUSÃO}

Através da experiência com a proposta metodológica na disciplina de HGPT-ET nas duas escolas do município de Petrópolis, foi possível identificar que existe a possibilidade de transformar o processo de construção do conhecimento dos alunos de forma mais interativa e dinâmica. Di Maio (2004) aponta que as aulas se tornam mais interessantes, a partir de metodologias de ensino onde o aluno é sujeito participante no processo de aprendizado. Porém, é preciso também ter a consciência de que estas novas tecnologias não garantem por si só a dinamização em sala de aula. No planejamento das aulas, o professor deve ter em mente que as geotecnologias são meios e recursos de forma que atenda aos objetivos propostos da aula, do tema a ser trabalhado, ao nível de conhecimento existente como aquele a ser construído pelos alunos (NISHIDA e PUERTA, 2007).

A ausência de infraestrutura nas escolas, sobretudo na rede pública de ensino, é vista como um elemento limitante para a aplicação de atividades que envolvam o uso das 
geotecnologias, mas não inviabiliza por completo o uso dessas ferramentas como mostra a aplicação da proposta na E. M. Dr. Rubens de Castro Bomtempo. Foi possível identificar com a proposta metodológica, que as geotecnologias associadas a metodologias participativas podem servir como um mecanismo de aproximação e maior conhecimento dos alunos em relação à história de fundação e organização espacial da cidade. A influência histórica de Petrópolis teve papel relevante no processo de escolha dos pontos de interesse dos alunos, de modo que o processo de pesquisa das informações pertinentes aos locais escolhidos permitiu que eles entendessem a complexidade das relações espaciais da cidade, e a partir do seu espaço vivido e produzido foi possível estimular o sentimento de pertencimento e identidade. Malyz (2007) afirma que o estudo do meio onde estamos inseridos, “(...) nos possibilita perceber a ação da sociedade no espaço e no tempo e também nos percebermos como sujeitos.” (p. 171).

Por fim, é válido destacar que a proposta metodológica não propõe substituir os conteúdos e tópicos abordados pela disciplina, mas contribuir como uma ferramenta alternativa de apoio para ser utilizada de forma conjunta e integrada aos conteúdos propostos e servir de material de consulta das turmas que realizaram a atividade e eventualmente das próximas turmas, proporcionando dessa maneira, novas formas de ensinar e aprender e, principalmente, perceber o espaço.

\section{REFERÊNCIAS BIBLIOGRÁFICAS}

ALMEIDA, R. D. e PASSINI, E. Y. O espaço geográfico: ensino e representação. São Paulo: Contexto:1994

ALVES, S. L. P. Mapeamento Colaborativo e a Geografia: delineamento e possibilidades. Rio de Janeiro, 2016. Monografia (Graduação em Geografia) Departamento de Geografia, Universidade Federal do Rio de Janeiro, Rio de Janeiro, 2016.

CASTELlAR, S. Noção de Espaço e Representação Cartográfica: ensino de Geografia nas séries iniciais. Tese (Doutorado) - Departamento de Geografia da Universidade de São Paulo, São Paulo, 1996.

CHAVES, C. M. S. R. S. Mapa da pesca artesanal da Baía de Guanabara: mapeamento participativo com pescadores artesanais da AHOMAR. 2011. 184 p. Dissertação (Mestrado em Geografia) - Departamento de Geografia, Universidade Federal do Rio de Janeiro. Rio de Janeiro, 2011.

DI MAIO, A. G. Geotecnologias Digitais no Ensino Médio: avaliação prática de seu potencial. 2004. 189 p. Tese (Doutorado em Geografia). Instituto de Geociências e Ciências Exatas, Universidade Estadual Paulista Júlio de Mesquita Filho.

MALYZ, S. T. Estágio em parceria universidade-educação básica. In: PASSINI, E. Y. et al. (2007). Prática de ensino de geografia e estágio supervisionado. Sção Paulo: Contexto, 2007, p. $16-25$.

MARTINELli, M. A sistematização da Cartografia Temática. In: ALMEIDA, R.D.Cartografia Escolar. São Paulo: Contexto, 2010. 
NISHIDA, P. B. e PUERTA, L. L. Multimídia na escola: formando o cidadão numa "cibersociedade". In: PASSINI, E. Y. et al. (2007). Prática de ensino de geografia e estágio supervisionado. São Paulo: Contexto, 2007, p. 124 - 131.

OLIVEIRA, M. M. A Geografia Escolar: Reflexões sobre o Processo DidáticoPedagógico do Ensino. Revista Discente Expressões Geográficas, Florianópolis, n. 02, p. 10-24, jun. 2006.

ROSA, R. Geotecnologias na Geografia aplicada. Revista do Departamento de Geografia, São Paulo, n.16, v.2, 2005.

SECRETARIA DE EDUCAÇÃO, PETRÓPOLIS. Referencial Curricular da Rede Municipal de Petrópolis: Segundo Segmento do Ensino Fundamental. Rio de Janeiro, 2014, 91 p.

SIMIELLI, M. E. R. Coleção Primeiros Mapas: como entender e construir. São Paulo: Ed. Ática, 1993.

VIEIRA, E. F. C. A Cartografia no processo de formação acadêmica do professor de Geografia. Tese (Doutorado) - Departamento de Geografia, Universidade de São Paulo, São Paulo, 2015, 235p. 